\title{
Formamidinium Lead Bromide (FAPbBr 3 ) Perovskite Microcrystals for Sensitive and Fast Photodetectors
}

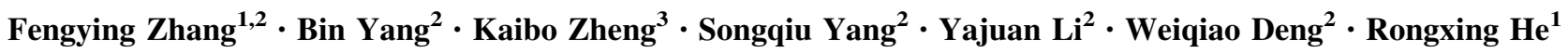

Received: 23 January 2018/Accepted: 5 March 2018/Published online: 2 April 2018

(C) The Author(s) 2018

\section{Highlights}

- Formamidinium lead trihalide $\left(\mathrm{FAPbBr}_{3}\right)$ microcrystal-based photodetectors facilitate efficient charge transfer.

- The fabricated $\mathrm{FAPbBr}_{3}$ photodetector shows good responsivity, external quantum efficiency, and detectivity.

- Two-photon performance of the photodetectors is better than that previously reported for $\mathrm{MAPbBr}_{3}$ photodetectors.

\begin{abstract}
Because of the good thermal stability and superior carrier transport characteristics of formamidinium lead trihalide perovskite $\mathrm{HC}\left(\mathrm{NH}_{2}\right)_{2} \mathrm{PbX}_{3}\left(\mathrm{FAPbX}_{3}\right)$, it has been considered to be a better optoelectronic material than conventional $\mathrm{CH}_{3} \mathrm{NH}_{3}$ $\mathrm{PbX}_{3}\left(\mathrm{MAPbX}_{3}\right)$. Herein, we fabricated a $\mathrm{FAPbBr}_{3}$ microcrystal-based photodetector that exhibited a good responsivity of $4000 \mathrm{~A} \mathrm{~W}^{-1}$ and external quantum efficiency up to $10^{6} \%$ under one-photon excitation, corresponding to the detectivity greater than $10^{14}$ Jones. The responsivity is two orders of magnitude higher than that of previously reported formamidinium perovskite photodetectors. Furthermore, the $\mathrm{FAPbBr}_{3}$
\end{abstract}

Electronic supplementary material The online version of this article (https://doi.org/10.1007/s40820-018-0196-2) contains supplementary material, which is available to authorized users.

Weiqiao Deng

dengwq@dicp.ac.cn

$\triangle$ Rongxing $\mathrm{He}$

herx@swu.edu.cn

1 Key Laboratory of Luminescence and Real-Time Analytical Chemistry of Ministry of Education, College of Chemistry and Chemical Engineering, Southwest University, Chongqing 400715, People's Republic of China

2 State Key Laboratory of Molecular Reaction Dynamics, Dalian Institute of Chemical Physics, Chinese Academy of Science, Dalian 116023, People's Republic of China

3 Department of Chemical Physics and NanoLund Chemical Center, Lund University, P.O. Box 124, 22100 Lund, Sweden
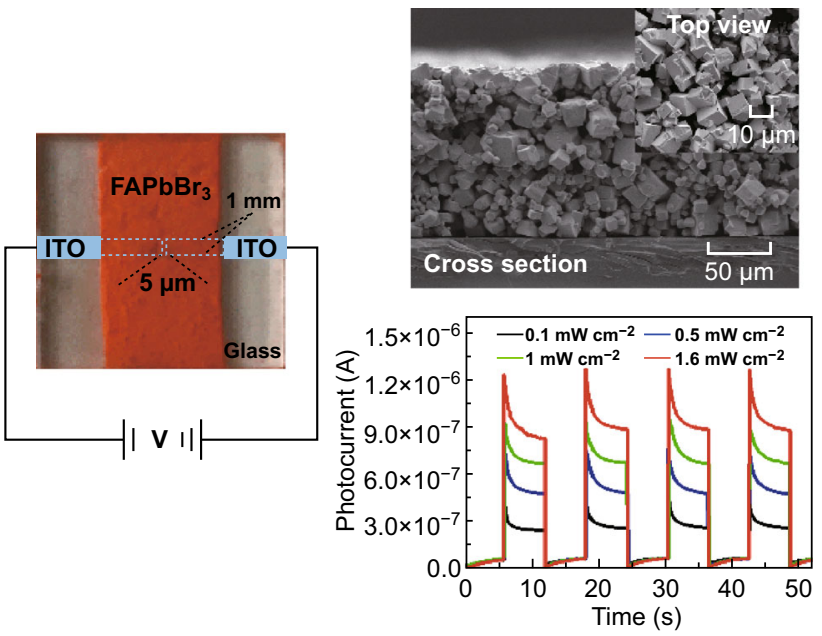

photodetector's responsivity to two-photon absorption with an 800-nm excitation source can reach $0.07 \mathrm{~A} \mathrm{~W}^{-1}$, which is four orders of magnitude higher than that of its $\mathrm{MAPbBr}_{3}$ counterparts. The response time of this photodetector is less than $1 \mathrm{~ms}$. This study provides solid evidence that $\mathrm{FAPbBr}_{3}$ can be an excellent candidate for highly sensitive and fast photodetectors.

Keywords Formamidinium lead trihalide $\left(\mathrm{FAPbBr}_{3}\right)$. Perovskite microcrystals $\cdot$ Photodetector $\cdot$ External quantum efficiency 


\section{Introduction}

In recent years, photoelectric devices have been widely investigated [1-3], especially detectors with different morphologies and sizes, for exploring their mechanisms, simplifying their syntheses, and improving device efficiencies [4-10]. Photodetectors based on hybrid organolead trihalide perovskite $\mathrm{CH}_{3} \mathrm{NH}_{3} \mathrm{PbX}_{3}\left(\mathrm{MAPbX}_{3}, \mathrm{X}=\mathrm{Cl}\right.$, $\mathrm{Br}$, I) have attracted significant attention in the optoelectronic field owing to their strong absorption coefficients (up to $\left.10^{5} \mathrm{~cm}^{-1}\right)$ [11-14], carrier mobilities $\left(2.5-1000 \mathrm{~cm}^{2}\right.$ $\left.\mathrm{v}^{-1} \mathrm{~s}^{-1}\right)$ [15-19], long carrier lifetimes $(0.08-4.5 \mu \mathrm{s})$ $[17,19-21]$, and diffusion lengths $(2-175 \mu \mathrm{m})$ $[19,20,22,23]$. In particular, Saidaminov et al. produced a planar-integrated photodetector using $\mathrm{MAPbBr}_{3}$ single crystals, achieving high-performance light detection in the wide wavelength range [24]. Bao et al. reported low-noise and large-linear-dynamic-range photodetectors based on $\mathrm{MAPbBr}_{3}$ and $\mathrm{MAPbI}_{3}$ [25]. Yang et al. demonstrated the great potential of metal-semiconductor-metal structures for low-cost and high-performance optoelectronic devices [26]. Moreover, $\mathrm{Hu}$ et al. [27] reported high-performance and low working-voltage perovskite thin-film photodetectors. Further, a UV-selective photodetector based on $\mathrm{MAPbCl}_{3}$ was also demonstrated [28, 29]. However, conventional $\mathrm{MAPbX}_{3}$ materials have poor stability [30, 31], which severely impedes device development.

$\mathrm{HC}\left(\mathrm{NH}_{2}\right)_{2} \mathrm{PbX}_{3} \quad\left(\mathrm{FAPbX}_{3}\right)$, which replaces organic methylammonium cation $\left(\mathrm{MA}^{+}\right)$with the larger formamidinium cation $\left(\mathrm{FA}^{+}\right)[32,33]$, is much more stable in air because the high Goldschmidt tolerance factor of its lattice $(\approx 1)$ [33-35]. Moreover, previous reports have revealed that FA-substituted compounds (e.g., FAPbX ${ }_{3}$ ) showed remarkably improved carrier transmission performance than $\mathrm{MAPbX}_{3}$ in both polycrystalline thin films and monocrystalline phases, including a longer carrier lifetime and lower dark carrier concentration [20, 22, 35-37]. As a result, $\mathrm{FAPbBr}_{3}$ is expected to perform better in photodetectors than $\mathrm{MAPbBr}_{3}$. However, a prototype device based on $\mathrm{FAPbBr}_{3}$ has not been reported yet, except for a twodimensional $(\mathrm{OA})_{2} \mathrm{FA}_{n-1} \mathrm{~Pb}_{n} \mathrm{Br}_{3 n+1}$ photodetector with low responsivity [38]. Taking advantage of the high carrier mobility, stability of single crystals and the efficient charge transfer in the micron scale, we synthesized $\mathrm{FAPbBr}_{3}$ microcrystals (MCs) and deposited them as a photodetector. Detailed investigations under single- and two-photon excitation and front- and back-side excitation were performed to reveal the great potential of the fabricated photodetector as an optoelectronic device.

\section{Experimental}

\subsection{Chemicals and Reagents}

Formamidine acetate, lead bromide $\left(\mathrm{PbBr}_{2},>98 \%\right)$ and hydrobromic acid (48 wt $\%$ in water) were purchased from Alfa Aesar. Gamma-butyrolactone (GBL) and N,Ndimethylformamide (DMF) were purchased from Kermel. All compounds were used without any further purification.

\subsection{Synthesis of $\mathrm{CH}\left(\mathrm{NH}_{2}\right)_{2} \mathrm{Br}(\mathrm{FABr})$}

FABr was synthesized by slowly dropping $10 \mathrm{~mL}$ hydrobromic acid into $50 \mathrm{mmol}(5.205 \mathrm{~g})$ formamidine acetate in a flask, accompanied by continuous stirring at $0{ }^{\circ} \mathrm{C}$ for $2 \mathrm{~h}$ under argon atmosphere. The product $\mathrm{FABr}$ was formed once the solvent was removed using a rotary evaporator at $70{ }^{\circ} \mathrm{C}$. The crude white powder was dissolved in ethanol and subsequently reprecipitated in diethyl ether. Then, the filtered product was dried at $60{ }^{\circ} \mathrm{C}$ in a vacuum oven for $24 \mathrm{~h}$ for further use.

\subsection{Synthesis of $\mathrm{FAPbBr}_{3} \mathrm{MCs}$}

$\mathrm{FAPbBr}_{3} \mathrm{MCs}$ were grown by a modified inverse temperature crystallization method using toluene as the antisolvent. In brief, $5 \mathrm{mmol} \mathrm{PbBr}_{2}(1.835 \mathrm{~g})$ and $5 \mathrm{mmol} \mathrm{FABr}$ $(0.625 \mathrm{~g})$ were dissolved in $10 \mathrm{~mL}$ mixed DMF:GBL (1:1 $\mathrm{v} / \mathrm{v})$ solvent at $25^{\circ} \mathrm{C}$, and the solution was filtered using nylon filters with a $0.22-\mu \mathrm{m}$ pore size. Then, $1 \mathrm{~mL}$ precursor was diluted in $2 \mathrm{~mL}$ DMF and antisolvent toluene was added to obtain a saturated solution. Single crystals of $\mathrm{FAPbBr}_{3}$ with millimeter dimensions were formed after stirring on a hot plate of $80{ }^{\circ} \mathrm{C}$.

\subsection{Device Preparation}

Standard photolithography and hydrochloric acid etching were used to obtain conductive glass substrates with a channel length and width of $5 \mu \mathrm{m}$ and $1 \mathrm{~mm}$, respectively. After synthesizing $\mathrm{FAPbBr}_{3} \mathrm{MCs}$ using the above-described method, the substrates were deposited on these crystals and dried at $160{ }^{\circ} \mathrm{C}$ for $10 \mathrm{~min}$.

\subsection{Measurements and Characterizations}

Scanning electron microscopy (SEM) was performed using a field-emission scanning electron microscope (JEOL, JSM-7800F, $3 \mathrm{kV}$ ). X-ray diffraction (XRD) was performed using an X'pert PRO diffractometer equipped with $\mathrm{Cu} \mathrm{K} \mathrm{K}_{\alpha} \mathrm{X}$-ray $(\lambda=1.54186 \AA)$ tubes. UV-Vis diffuse reflectance spectra were recorded at room temperature on a 
JASCO V-550 UV-Vis absorption spectrometer with an integrating sphere operating in 200-900 nm. Photoluminescence (PL) was recorded using a Horiba PTI QuantaMaster 400 system with an excitation of $470 \mathrm{~nm}$. Timeresolved PL decay was obtained on the basis of the timecorrelated single-photon counter (TCSPC) technology using a light-emitting diode (LED) to provide a 376-nm excitation beam. The decay data were analyzed using commercial software provided by Horiba. For trap-state density evaluation, one layer of conductive glass (ITO) undertaken the crystal film was used as one electrode. An 800-nm-thick gold ( $\mathrm{Au}$ ) layer deposited on top of the film by thermal evaporation was used as the other electrode. This structure had a rather simple geometry with the sample deposited on ITO and evaporated Au on opposite sides, and the structure should be kept in the dark. Currentvoltage measurements were conducted using a Keithley 2400 source meter. For light characterization under onephoton excitation, a monochromatic source (LED, $\lambda=495 \mathrm{~nm})$ was used. Spectral responsivity $(R)$ was calculated by the photocurrent $\left(I_{\mathrm{ph}}\right)$ and incident power $\left(P_{\mathrm{inc}}\right)$ according to the relation $R=I_{\mathrm{ph}} / P_{\text {inc }}$. For two-photon irradiation, the photocurrent was generated using a femtosecond laser system (Spitfire Pro, SpectraPhysic) with an output wavelength of $800 \mathrm{~nm}$ and a repetition rate of $1000 \mathrm{~Hz}$ as the light source.

\section{Results and Discussion}

We synthesized $\mathrm{FAPbBr}_{3}$ MCs using a modified antisolvent-assisted inverse temperature crystallization method [8, 24, 28]. To facilitate the removal of the solvent and form homogeneous crystalline films, $1 \mathrm{M}$ precursor (equimolar $\mathrm{FABr}$ and $\mathrm{PbBr}_{2}$ dissolved in a mixed solvent as shown in experimental section) was diluted three times in DMF. The antisolvent toluene was then added to obtain a saturated solution. This saturated solution was stirred at $80{ }^{\circ} \mathrm{C}$ to accelerate the nucleation and increase the yield of the interconnected crystals. The mean size of the as-obtained $\mathrm{FAPbBr}_{3} \mathrm{MCs}$ was $\sim 10 \pm 5 \mu \mathrm{m}$, as shown in the top-view SEM image (Fig. 1a). These MCs were interconnected as a continuous film with a thickness of $\sim 150 \mu \mathrm{m}$, as shown in Fig. 1b. XRD results shown in Fig. 1c confirmed the cubic phase of the $\mathrm{FAPbBr}_{3} \mathrm{MCs}$ [35, 39]. The MCs exhibited an absorption band edge at $570 \mathrm{~nm}$, corresponding to a bandgap of $2.18 \mathrm{eV}$, as obtained from the Tauc plot of the absorption spectrum (Fig. 1d). The emission peak of the MCs appeared at $567 \mathrm{~nm}$ (insets of Fig. 1d), which was consistent with previous results $[33,37,40]$. Additionally, PL decay was measured using the TCSPC technology (Fig. 1e), and a fast component $\left(\tau_{1}, 15 \pm 1 \mathrm{~ns}\right)$ and slow decay $\left(\tau_{2}\right.$, $282 \pm 5 \mathrm{~ns}$ ) reflected the surface and bulk carrier lifetimes
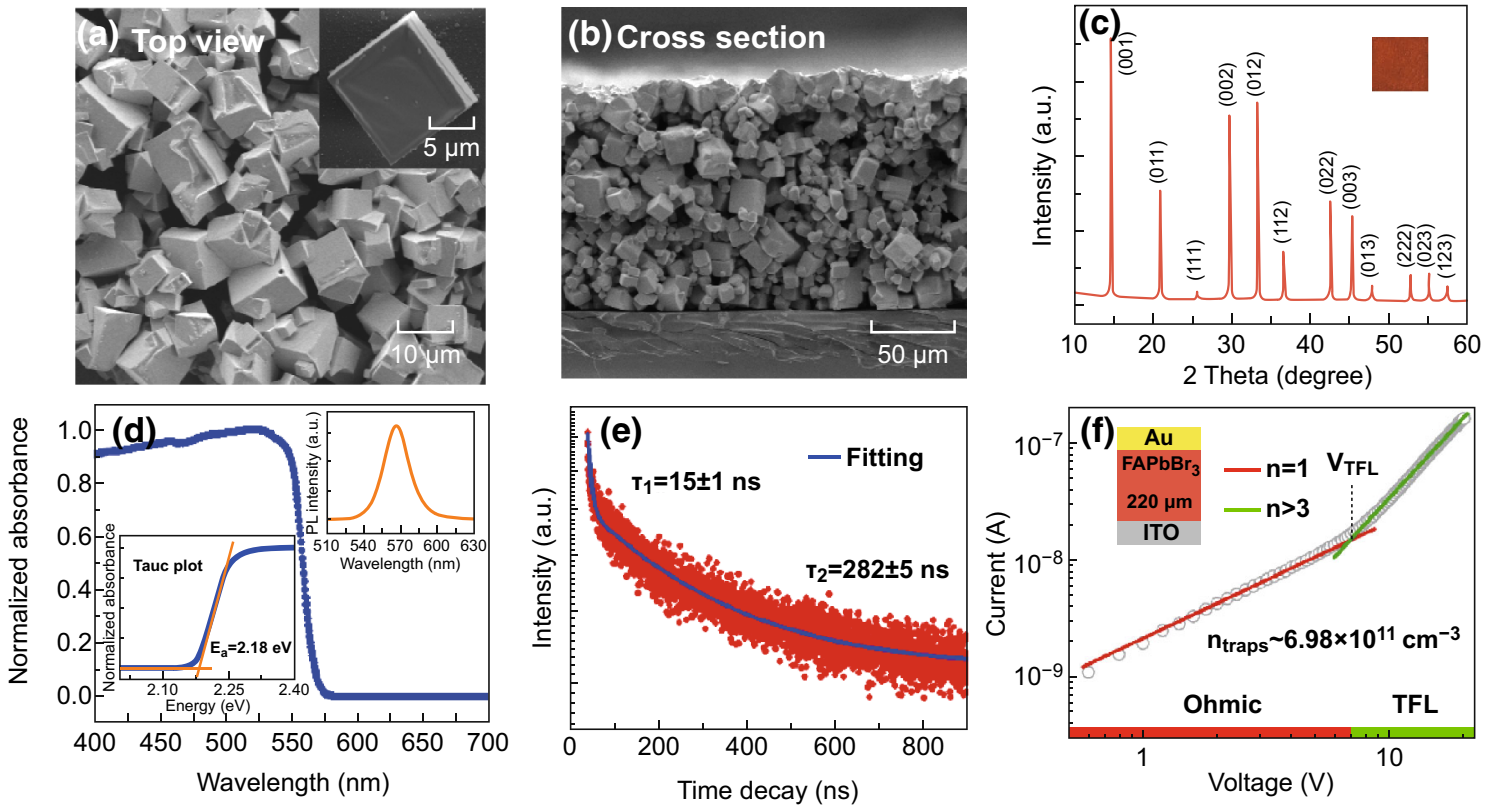

Fig. 1 a Top-view and $\mathbf{b}$ cross-sectional SEM images. $\mathbf{c}$ XRD pattern $\mathbf{d}$ Steady-state absorption spectrum of FAPbBr $\mathrm{FCs}_{3} \mathrm{MC}_{\mathrm{ilm}}$. Left insets: the optical bandgap extracted from Tauc plot; right insets: PL spectrum. e PL decay of the sample excited at 376 nm, which could be well fitted by biexponential functions. f Current-voltage responses of $\mathrm{FAPbBr}_{3} \mathrm{MCs}$ 
of the $\mathrm{FAPbBr}_{3} \mathrm{MCs}$, respectively. We also conducted dark current measurements to estimate the trap-state density of the $\mathrm{FAPbBr}_{3} \mathrm{MC}$ film, as depicted in Fig. 1f. Here, the trap-state density was calculated to be $6.98 \times 10^{11} \mathrm{~cm}^{-3}$ according to Eq.1:

$n_{\text {trap }}=\frac{2 \varepsilon_{0} \varepsilon V_{\mathrm{TFL}}}{q L^{2}}$

where $V_{\mathrm{TFL}}$ is the voltage at which trap states are fully filled by injected carriers, $q$ and $L$ represent the elemental charge and film thickness, respectively, $\varepsilon_{0}$ and $\varepsilon$ denote the vacuum permittivity and dielectric constant of $\mathrm{FAPbBr}_{3}$, with $\varepsilon=43.6$ [37]. The relatively fewer defects contributed to the formation of a high-quality film, thus promoting their application in photoelectronic devices [37, 41].

In the next step, $\mathrm{FAPbBr}_{3} \mathrm{MCs}$ were directly deposited on interdigitated ITO substrates to form the prototype photodetector device. The length and width of the gaps between neighboring digits were $5 \mu \mathrm{m}$ and $1 \mathrm{~mm}$, respectively, as shown in Fig. S1. FAPbBr 3 MCs covered the entire active area, forming Schottky barriers due to contact with the ITO electrode. Once a voltage was applied to the detector device, ion migration and carrier trapping occurred in the active layer and at the electrode/perovskite interfaces, respectively. This indicated that an Ohmic contact between the $\mathrm{FAPbBr}_{3} \mathrm{MCs}$ and the ITO electrode was formed. The cathode collected abundant photogenerated holes, while holes from the anode were injected into the active layer, showing the photoconductivity of the device [42-44]. The compact morphology of the MCs minimized the grain boundary and consequently diminished interfacial charge recombination. As shown in Fig. 2a, the photocurrent drastically increased with increasing excitation light intensity. In addition, the small dark current of the device (seen in Fig. S2) indicated the low carrier concentration of $\mathrm{FAPbBr}_{3} \mathrm{MCs}$ [37]. The photoresponse was also reproducible under a periodic excitation of the light pulse, as demonstrated in Fig. S3.

As shown in Fig. 2b, the photocurrent increased linearly with the incident power and the corresponding responsivity ( $R$, defined as photocurrent/the incident light power) linearly decreased. The responsivity was $4000 \mathrm{~A} \mathrm{~W}^{-1}$ at $5 \mathrm{~V}$ $\left(\lambda=495 \mathrm{~nm}\right.$, probe intensity $\left.=10 \mathrm{nW} \mathrm{cm}^{-2}\right)$, which was two orders of magnitude higher than that of other FA-based perovskite photodetectors [7, 38, 45, 46]. Furthermore, the external quantum efficiency (EQE) calculated by Eq. 2 was as high as $1.05 \times 10^{6} \%$ (Fig. $2 \mathrm{c}$ ):

$\mathrm{EQE}=\frac{R \cdot \mathrm{hc}}{q \lambda}$

In addition, the detectivity $D^{*}$ of the device was $3.87 \times 10^{14}$ Jones, as obtained from Eq. 3:

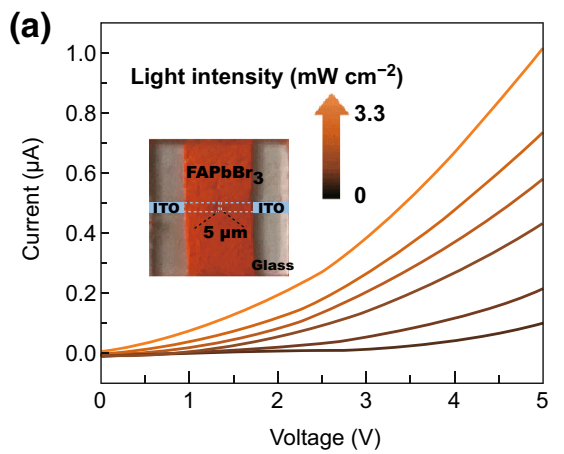

(c)

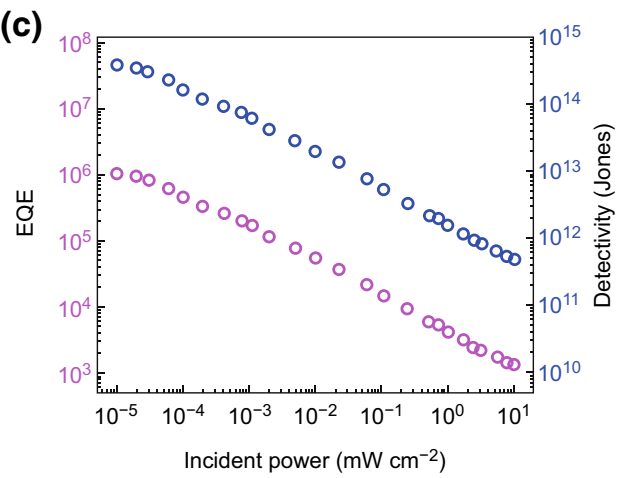

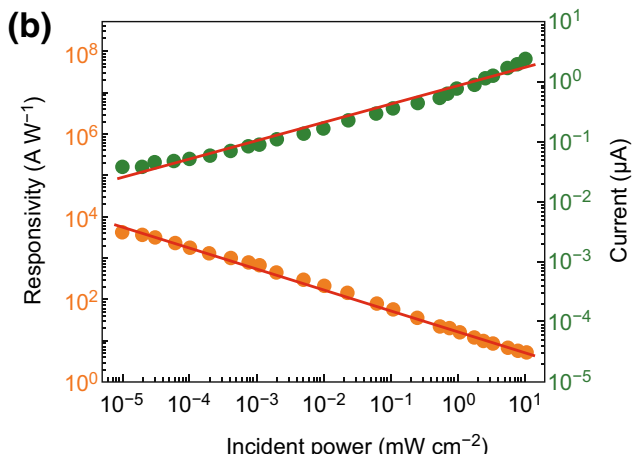

(d)

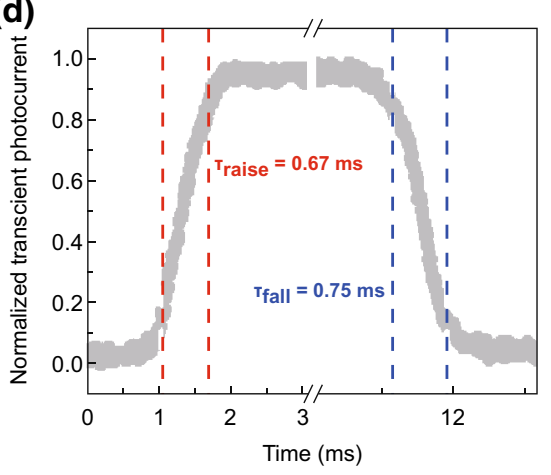

Fig. 2 a Current-voltage characteristics measured under back-side excitation with varying light intensity. b Responsivity and corresponding current as a function of incident light power under back-side illumination. The detector was biased at $5 \mathrm{~V}$. c EQE and detectivity under different light illuminations. d Response time measured by a monochromatic source of $495 \mathrm{~nm}$ under back-side illumination and rise time and fall time 
$D^{*}=\frac{R \sqrt{A}}{\sqrt{q I_{\text {dark }}}}$

This value of $D^{*}$ was higher than that of state-of-art $\mathrm{MAPbI}_{3}$ photodetectors $\left(\sim 10^{13}\right.$ Jones $)$ [46]. Moreover, the $\mathrm{FAPbBr}_{3} \mathrm{MC}$ photodetector exhibited a rapid response with a rise time $\left(\tau_{\text {rise }}\right)$ of $0.67 \mathrm{~ms}$ and fall time $\left(\tau_{\text {fall }}\right)$ of $0.75 \mathrm{~ms}$ (Figs. $2 \mathrm{~d}$ and S4), where $\tau_{\text {rise }}$ and $\tau_{\text {fall }}$ are defined as the time required for light response from 10 to $90 \%$ in the rising stage and from 90 to $10 \%$ in the falling stage, respectively.

Previous research has revealed that the photoresponse to the excitation wavelength is different for front-side excitation and back-side excitation [46]. In back-side excitation, charge carriers are efficiently collected in the vicinity of the electrodes. However, in front-side excitation, it is more difficult for charge carriers generated by shortwavelength photons to penetrate the thick film to electrodes than that of long-wavelength photons with energy comparable to the bandgap [46]. In our case, the wavelengthdependent light response using front-side excitation resembled that using back-side excitation, indicating that our device was a broadband photodetector (Figs. 3a and S5). It was found that the thickness of the $\mathrm{FAPbBr}_{3}$ microcrystalline film of about $150 \mu \mathrm{m}$ allowed most photons to be transmitted through the film to generate corresponding photocurrents. Once the film became sufficiently thick $(>200 \mu \mathrm{m})$, it blocked the short-wavelength photons to the microcrystalline film to form a narrowband photodetector, which was also confirmed by Saidaminov and coworkers [46]. In addition, the generally lower photocurrent for front-side excitation could be attributed to the insufficient diffusion length of the photogenerated charges for the given film thickness, which hindered charge transportation to the bottom electrode [46]. Figure $3 b$ shows the photocurrent variation for different bias voltages. As shown in Fig. 3c, d, when the bias voltage was decreased, the photocurrents of the photons excited far above the absorption band edge degraded more.

Perovskites have also attracted considerable attention as nonlinear semiconductor absorbers for optical limiting [47], ultrafast optical signal characterization [48], microscopy [49], and lithography [50]. Therefore, we characterized our device under two-photon excitation, where the photocurrent was generated by an $800-\mathrm{nm}$ pulse laser with a photon energy much smaller than the bandgap of $\mathrm{FAPbBr}_{3}(2.18 \mathrm{eV})$. Figure $4 \mathrm{a}$ shows the PL mechanism of $\mathrm{FAPbBr}_{3}$ at $567 \mathrm{~nm}$ obtained under 800-nm two-photon absorption. Under 800-nm back-side illumination at a fixed bias of $5 \mathrm{~V}$, the tendency of light current variation with
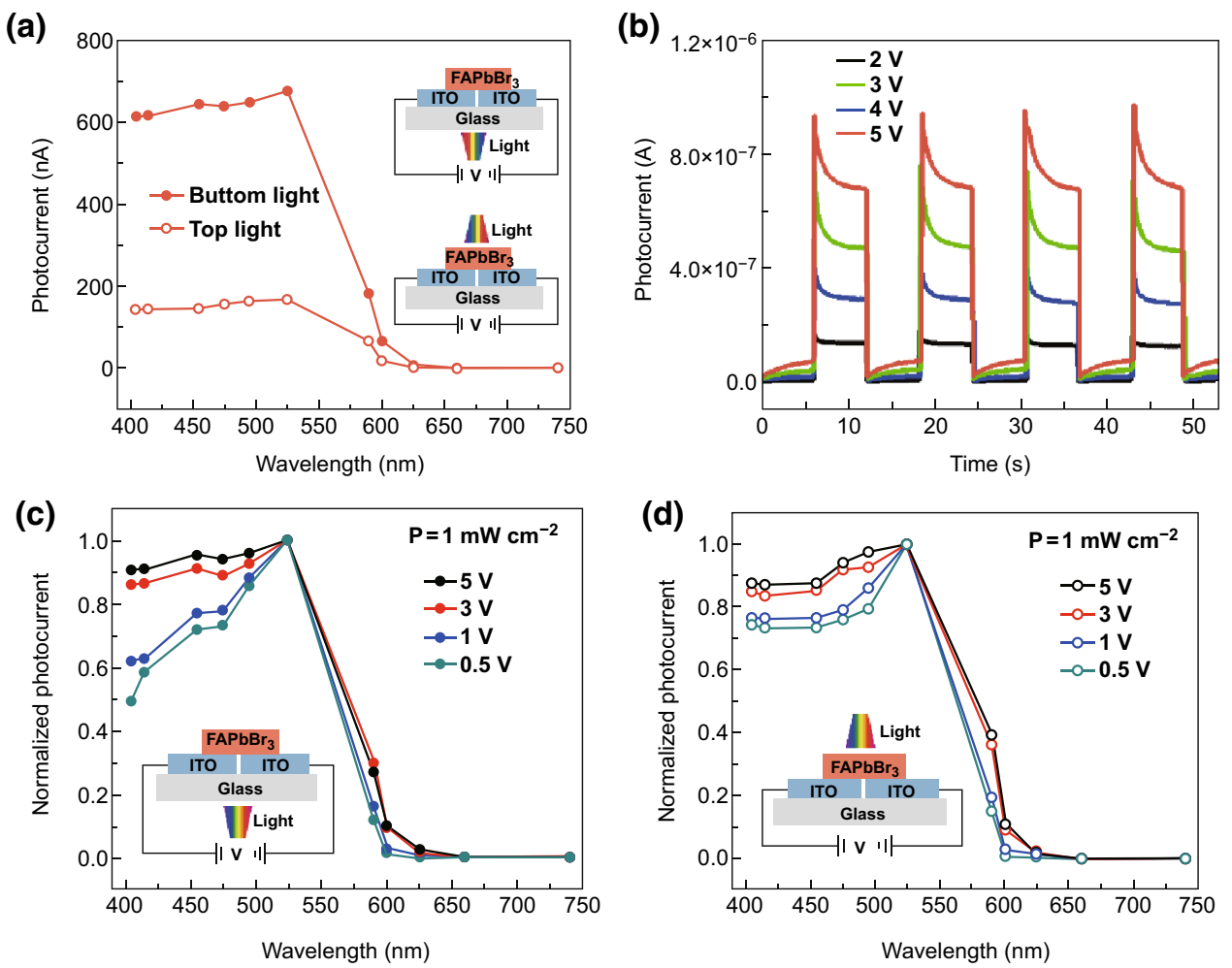

Fig. 3 a Spectral-dependent photocurrent under front-side and back-side excitation at $1 \mathrm{~mW} \mathrm{~cm}{ }^{-2}$ and a bias voltage of $5 \mathrm{~V}$. b Photocurrent response measured using a series of bias voltages: 2, 3, 4, and $5 \mathrm{~V}$, at an excitation of $495 \mathrm{~nm}$. Normalized spectral-dependent photocurrent under different bias voltages under $\mathbf{c}$ back-side and $\mathbf{d}$ front-side excitation 

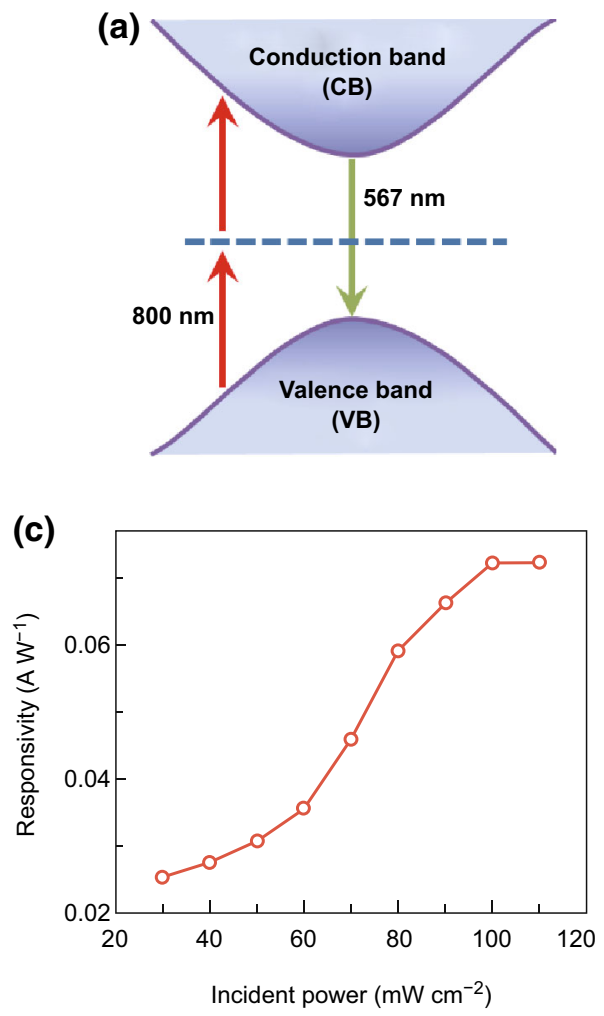

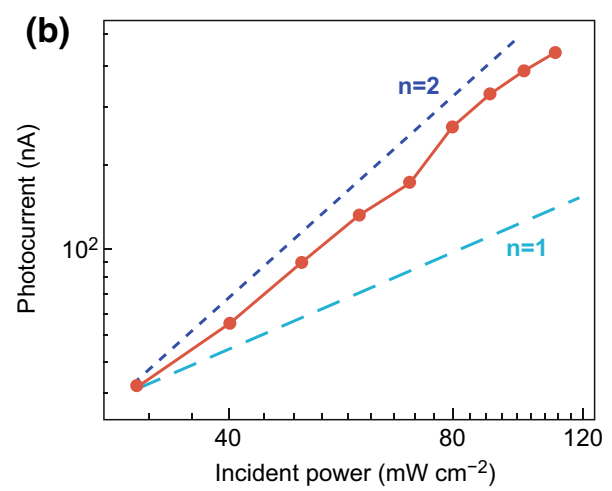

(d)

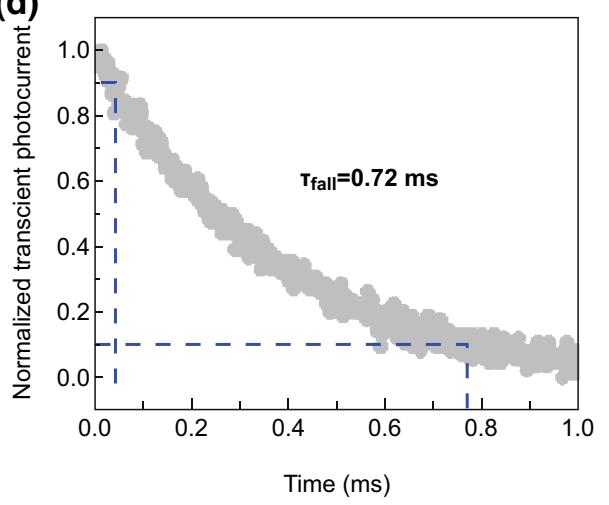

Fig. 4 a Schematic showing two-photon absorption of $800 \mathrm{~nm}$ light and up-conversion to $567 \mathrm{~nm}$ PL. b Photocurrent and c responsivity dependence at an input light intensity of $800 \mathrm{~nm}$ and a bias of 5 V.d Fall time measured using pulsed light of $800 \mathrm{~nm}$

respect to voltage $\left(30-110 \mathrm{~mW} \mathrm{~cm}^{-2}\right)$ is provided in Fig. 4b. Under ideal conditions, the photocurrent generated by two-photon absorption showed a square $(n=2)$ dependence on the input intensity [51]. However, our tested photocurrents (with $1<n<2$ ) exhibited highly dependent on incident power, which was mainly attributed to the effect of trap-state's sub-gap absorption $[8,52]$. This tendency was consistent with that reported for near-infrared $\mathrm{CsPbBr}_{3}$ and $\mathrm{MAPbBr}_{3}$ photodetectors [8, 51]. Consequently, the responsivity of the two-photon pumped $\mathrm{FAPbBr}_{3} \mathrm{MC}$ detector increased with increasing input intensity in the linear excitation region (Fig. 4c). The largest responsivity under $800-\mathrm{nm}$ excitation $\left(0.07 \mathrm{~A} \mathrm{~W}^{-1}\right)$ was much higher than that previously reported for $\mathrm{MAPbBr}_{3}$ single crystals [51]. The fast response of our detector under two-photon excitation with a fast fall time $(0.72 \mathrm{~ms})$ is also shown in Fig. $4 \mathrm{~d}$. The result is similar to that observed under one-photon excitation $(0.75 \mathrm{~ms})$. The rapid pulse light with periodic changes was responsible for the missing rising stage.

Moreover, the amplified spontaneous emission (ASE) behavior of the $\mathrm{FAPbBr}_{3}$ microcrystalline film was measured using 800-nm laser pulses with tunable intensities. The emission spectra (Fig. S6) with increasing light intensity exhibited an ASE threshold of $1.75 \mathrm{~mJ} \mathrm{~cm}^{-2}$, which was similar to the reported two-photon ASE threshold of $\mathrm{MAPbBr}_{3}$ photodetectors $\left(2.2 \mathrm{~mJ} \mathrm{~cm}^{-2}\right)$ [53].

\section{Conclusion}

In summary, organolead trihalide perovskite $\mathrm{FAPbBr}_{3} \mathrm{MCs}$ were synthesized and then deposited as a photodetector. The photodetector exhibited a good responsivity of up to $4000 \mathrm{~A} \mathrm{~W}^{-1}$ under back-side one-photon excitation with an EQE and detectivity of up to $1.05 \times 10^{6} \%$ and $3.87 \times 10^{14}$ Jones, respectively. Besides, the two-photon responsivity under $800-\mathrm{nm}$ excitation was $0.07 \mathrm{~A} \mathrm{~W}^{-1}$, which was four orders of magnitude higher than that reported for $\mathrm{MAPbBr}_{3}$ single crystals $\left(10^{-6} \mathrm{~A} \mathrm{~W}^{-1}\right)$. This deposited $\mathrm{FAPbBr}_{3}$ microcrystalline photodetector showed great potential for developing fast and sensitive photodetectors.

Acknowledgements We would like to acknowledge all funding sources, including grant numbers and funding agencies. We are grateful to the National Key R@D Program of China (Grant 2017YFA0204800) and the National Natural Science Foundation of China (Grant Nos: 21533010, 21321091, 21525315, 91333116 and 21173169) for their financial supports. 
Open Access This article is distributed under the terms of the Creative Commons Attribution 4.0 International License (http://crea tivecommons.org/licenses/by/4.0/), which permits unrestricted use, distribution, and reproduction in any medium, provided you give appropriate credit to the original author(s) and the source, provide a link to the Creative Commons license, and indicate if changes were made.

\section{References}

1. W. Zhao, X. Xiong, Y. Han, L. Wen, Z. Zou et al., Fe-doped $\mathrm{p}-\mathrm{ZnO}$ nanostructures/n-gan heterojunction for "blue-free" orange light-emitting diodes. Adv. Opt. Mater. 5(17), 1700146 (2017). https://doi.org/10.1002/adom.201700146

2. G. Li, Z.K. Tan, D. Di, M.L. Lai, L. Jiang, J.H. Lim, R.H. Friend, N.C. Greenham, Efficient light-emitting diodes based on nanocrystalline perovskite in a dielectric polymer matrix. Nano Lett. 15(4), 2640-2644 (2015). https://doi.org/10.1021/acs.nano lett.5b00235

3. W.S. Yang, J.H. Noh, N.J. Jeon, Y.C. Kim, S. Ryu, J. Seo, S.I. Seok, High-performance photovoltaic perovskite layers fabricated through intermolecular exchange. Science 348, 1234-1237 (2015). https://doi.org/10.1126/science.aaa9272

4. Y. Wang, Y. Chen, W. Zhao, L. Ding, L. Wen et al., A selfpowered fast-response ultraviolet detector of p-n homojunction assembled from two ZnO-based nanowires. Nano-Micro Lett. 9, 11 (2016). https://doi.org/10.1007/s40820-016-0112-6

5. Z. Kang, Y. Ma, X. Tan, M. Zhu, Z. Zheng et al., MXene-silicon van der waals heterostructures for high-speed self-driven photodetectors. Adv. Electron. Mater. 3(9), 1700165 (2017). https:// doi.org/10.1002/aelm.201700165

6. X. Zhang, X. Han, J. Su, Q. Zhang, Y. Gao, Well vertically aligned $\mathrm{ZnO}$ nanowire arrays with an ultra-fast recovery time for UV photodetector. Appl. Phys. A 107(2), 255-260 (2012). https:// doi.org/10.1007/s00339-012-6886-6

7. S. Li, S. Tong, J. Yang, H. Xia, C. Zhang et al., High-performance formamidinium-based perovskite photodetectors fabricated via doctor-blading deposition in ambient condition. Org. Electron. 47, 102-107 (2017). https://doi.org/10.1016/j.orgel. 2017.05.010

8. B. Yang, F. Zhang, J. Chen, S. Yang, X. Xia, T. Pullerits, W. Deng, K. Han, Ultrasensitive and fast all-inorganic perovskitebased photodetector via fast carrier diffusion. Adv. Mater. 29, 1703758 (2017). https://doi.org/10.1002/adma.201703758

9. X. Zhang, S. Yang, H. Zhou, J. Liang, H. Liu et al., Perovskiteerbium silicate nanosheet hybrid waveguide photodetectors at the near-infrared telecommunication band. Adv. Mater. 29(21), 1604431 (2017). https://doi.org/10.1002/adma.201604431

10. D. Dong, H. Deng, C. Hu, H. Song, K. Qiao et al., Bandgap tunable $\mathrm{Cs}_{\mathrm{x}}\left(\mathrm{CH}_{3} \mathrm{NH}_{3}\right)_{1-\mathrm{x}} \mathrm{PbI}_{3}$ perovskite nanowires by aqueous solution synthesis for optoelectronic devices. Nanoscale 9(4), 1567-1574 (2017). https://doi.org/10.1039/C6NR06636D

11. Q. Chen, N. De Marco, Y.M. Yang, T.B. Song, C.C. Chen, H. Zhao, Z. Hong, H. Zhou, Y. Yang, Under the spotlight: the organic-inorganic hybrid halide perovskite for optoelectronic applications. Nano Today 10(3), 355-396 (2015). https://doi.org/ 10.1016/j.nantod.2015.04.009

12. J. Zhang, X. Yang, H. Deng, K. Qiao, U. Farooq et al., Lowdimensional halide perovskites and their advanced optoelectronic applications. Nano-Micro Lett. 9(3), 36 (2017). https://doi.org/10. 1007/s40820-017-0137-5

13. J.S. Manser, J.A. Christians, P.V. Kamat, Intriguing optoelectronic properties of metal halide perovskites. Chem. Rev.
116(21), 12956-13008 (2016). https://doi.org/10.1021/acs.chem rev.6b00136

14. M.A. Green, A. Ho-Baillie, H.J. Snaith, The emergence of perovskite solar cells. Nat. Photonics 8(7), 506-514 (2014). https:// doi.org/10.1038/nphoton.2014.134

15. G. Xing, N. Mathews, S. Sun, S.S. Lim, Y.M. Lam, M. Grätzel, S. Mhaisalkar, T.C. Sum, Long-range balanced electron-and holetransport lengths in organic-inorganic $\mathrm{CH}_{3} \mathrm{NH}_{3} \mathrm{PbI}_{3}$. Science 342(6156), 344-347 (2013). https://doi.org/10.1126/science. 1243167

16. W. Zhang, M. Saliba, D.T. Moore, S.K. Pathak, M.T. Hörantner et al., Ultrasmooth organic-inorganic perovskite thin-film formation and crystallization for efficient planar heterojunction solar cells. Nat. Commun. 6, 6142 (2015). https://doi.org/10.1038/ ncomms 7142

17. C. Wehrenfennig, G.E. Eperon, M.B. Johnston, H.J. Snaith, L.M. Herz, High charge carrier mobilities and lifetimes in organolead trihalide perovskites. Adv. Mater. 26(10), 1584-1589 (2014). https://doi.org/10.1002/adma.201305172

18. D.A. Valverde-Chávez, C.S. Ponseca, C.C. Stoumpos, A. Yartsev, M.G. Kanatzidis, V. Sundström, D.G. Cooke, Intrinsic femtosecond charge generation dynamics in single crystal $\mathrm{CH}_{3}$ $\mathrm{NH}_{3} \mathrm{PbI}_{3}$. Energy Environ. Sci. 8(12), 3700-3707 (2015). https:// doi.org/10.1039/C5EE02503F

19. D.N. Dirin, I. Cherniukh, S. Yakunin, Y. Shynkarenko, M.V. Kovalenko, Solution-grown $\mathrm{Cs} \mathrm{PbBr} 3$ perovskite single crystals for photon detection. Chem. Mater. 28(23), 8470-8474 (2016). https://doi.org/10.1021/acs.chemmater.6b04298

20. D. Shi, V. Adinolfi, R. Comin, M. Yuan, E. Alarousu et al., Low trap-state density and long carrier diffusion in organolead trihalide perovskite single crystals. Science 347(6221), 519-522 (2015). https://doi.org/10.1126/science.aaa2725

21. M.I. Saidaminov, A.L. Abdelhady, B. Murali, E. Alarousu, V.M. Burlakov et al., High-quality bulk hybrid perovskite single crystals within minutes by inverse temperature crystallization. Nat. Commun. 6, 7586 (2015). https://doi.org/10.1038/ ncomms 8586

22. Q. Dong, Y. Fang, Y. Shao, P. Mulligan, J. Qiu, L. Cao, J. Huang, Electron-hole diffusion lengths $>175 \mu \mathrm{m}$ in solution-grown $\mathrm{CH}_{3} \mathrm{NH}_{3} \mathrm{PbI}_{3}$ single crystals. Science 347(6225), 967-970 (2015). https://doi.org/10.1126/science.aaa5760

23. S.D. Stranks, G.E. Eperon, G. Grancini, C. Menelaou, M.J. Alcocer, T. Leijtens, L.M. Herz, A. Petrozza, H.J. Snaith, Electron-hole diffusion lengths exceeding 1 micrometer in an organometal trihalide perovskite absorber. Science 342(6156), 341-344 (2013). https://doi.org/10.1126/science.1243982

24. M.I. Saidaminov, V. Adinolfi, R. Comin, A.L. Abdelhady, W. Peng et al., Planar-integrated single-crystalline perovskite photodetectors. Nat. Commun. 6, 8724 (2015). https://doi.org/10. 1038/ncomms9724

25. C. Bao, Z. Chen, Y. Fang, H. Wei, Y. Deng, X. Xiao, L. Li, J. Huang, Low-noise and large-linear-dynamic-range photodetectors based on hybrid-perovskite thin-single-crystals. Adv. Mater. 29(39), 1703209 (2017). https://doi.org/10.1002/adma. 201703209

26. J. Yang, T. Yu, K. Zhu, Q. Xu, High-gain and fast-response metal-semiconductor-metal structured organolead halide perovskite photodetectors. J. Phys. D Appl. Phys. 50(49), 495102 (2017). https://doi.org/10.1088/1361-6463/aa918c

27. W. Hu, R. Wu, S. Yang, P. Fan, J. Yang, A. Pan, Solvent-induced crystallization for hybrid perovskite thin-film photodetector with high-performance and low working voltage. J. Phys. D Appl. Phys. 50(37), 375101 (2017). https://doi.org/10.1088/1361-6463/ aa8059

28. V. Adinolfi, O. Ouellette, M.I. Saidaminov, G. Walters, A.L. Abdelhady, O.M. Bakr, E.H. Sargent, Fast and sensitive solution- 
processed visible-blind perovskite uv photodetectors. Adv. Mater. 28(33), 7264-7268 (2016). https://doi.org/10.1002/adma. 201601196

29. G. Maculan, A.D. Sheikh, A.L. Abdelhady, M.I. Saidaminov, M.A. Haque et al., $\mathrm{CH}_{3} \mathrm{NH}_{3} \mathrm{PbCl}_{3}$ single crystals: inverse temperature crystallization and visible-blind uv-photodetector. J. Phys. Chem. Lett. 6(19), 3781-3786 (2015). https://doi.org/10. 1021/acs.jpclett.5b01666

30. T.B. Song, Q. Chen, H. Zhou, C. Jiang, H.H. Wang, Y.M. Yang, Y. Liu, J. You, Y. Yang, Perovskite solar cells: film formation and properties. J. Mater. Chem. A 3(17), 9032-9050 (2015). https://doi.org/10.1039/C4TA05246C

31. X. Li, M.I. Dar, C. Yi, J. Luo, M. Tschumi, S.M. Zakeeruddin, M.K. Nazeeruddin, H. Han, M. Grätzel, Improved performance and stability of perovskite solar cells by crystal crosslinking with alkylphosphonic acid $\omega$-ammonium chlorides. Nat. Chem. 7(9), 703-711 (2015). https://doi.org/10.1038/nchem.2324

32. T.M. Koh, K. Fu, Y. Fang, S. Chen, T. Sum, N. Mathews, S.G. Mhaisalkar, P.P. Boix, T. Baikie, Formamidinium-containing metal-halide: an alternative material for near-IR absorption perovskite solar cells. J. Phys. Chem. C 118(30), 16458-16462 (2013). https://doi.org/10.1021/jp411112k

33. G.E. Eperon, S.D. Stranks, C. Menelaou, M.B. Johnston, L.M. Herz, H.J. Snaith, Formamidinium lead trihalide: a broadly tunable perovskite for efficient planar heterojunction solar cells. Energy Environ. Sci. 7(3), 982-988 (2014). https://doi.org/10. 1039/C3EE43822H

34. T.J. Jacobsson, J.P. Correa-Baena, M. Pazoki, M. Saliba, K. Schenk, M. Grätzel, A. Hagfeldt, Exploration of the compositional space for mixed lead halogen perovskites for high efficiency solar cells. Energy Environ. Sci. 9(5), 1706-1724 (2016). https://doi.org/10.1039/C6EE00030D

35. F.C. Hanusch, E. Wiesenmayer, E. Mankel, A. Binek, P. Angloher et al., Efficient planar heterojunction perovskite solar cells based on formamidinium lead bromide. J. Phys. Chem. Lett. 5(16), 2791-2795 (2014). https://doi.org/10.1021/jz501237m

36. N. Pellet, P. Gao, G. Gregori, T.Y. Yang, M.K. Nazeeruddin, J. Maier, M. Grätzel, Mixed-organic-cation perovskite photovoltaics for enhanced solar-light harvesting. Angew. Chem. Int. Edit. 53(12), 3151-3157 (2014). https://doi.org/10.1002/anie. 201309361

37. A.A. Zhumekenov, M.I. Saidaminov, M.A. Haque, E. Alarousu, S.P. Sarmah et al., Formamidinium lead halide perovskite crystals with unprecedented long carrier dynamics and diffusion length. ACS Energy Lett. 1(1), 32-37 (2016). https://doi.org/10.1021/ acsenergylett.6b00002

38. D. Yu, F. Cao, Y. Shen, X. Liu, Y. Zhu, H. Zeng, Dimensionality and interface engineering of $2 \mathrm{~d}$ homologous perovskites for boosted charge-carrier transport and photodetection performances. J. Phys. Chem. Lett. 8(12), 2565-2572 (2017). https:// doi.org/10.1021/acs.jpclett.7b00993

39. M.I. Saidaminov, A.L. Abdelhady, G. Maculan, O.M. Bakr, Retrograde solubility of formamidinium and methylammonium lead halide perovskites enabling rapid single crystal growth. Chem. Commun. 51(100), 17658-17661 (2015). https://doi.org/ 10.1039/C5CC06916E

40. N. Arora, M.I. Dar, M. Hezam, W. Tress, G. Jacopin et al., Photovoltaic and amplified spontaneous emission studies of high- quality formamidinium lead bromide perovskite films. Adv. Funct. Mater. 26(17), 2846-2854 (2016). https://doi.org/10.1002/ adfm. 201504977

41. Q. Han, S.H. Bae, P. Sun, Y.T. Hsieh, Y.M. Yang et al., Single crystal formamidinium lead iodide $\left(\mathrm{FAPbI}_{3}\right)$ : insight into the structural, optical, and electrical properties. Adv. Mater. 28(11), 2253-2258 (2016). https://doi.org/10.1002/adma.201505002

42. R. Dong, Y. Fang, J. Chae, J. Dai, Z. Xiao et al., High-gain and low-driving-voltage photodetectors based on organolead triiodide perovskites. Adv. Mater. 27(11), 1912-1918 (2015). https://doi. org/10.1002/adma.201405116

43. W. Hu, W. Huang, S. Yang, X. Wang, Z. Jiang et al., Highperformance flexible photodetectors based on high-quality perovskite thin films by a vapor-solution method. Adv. Mater. 29(43), $1703256 \quad$ (2017). https://doi.org/10.1002/adma. 201703256

44. M. Ahmadi, T. Wu, B. Hu, A review on organic-inorganic halide perovskite photodetectors: device engineering and fundamental physics. Adv. Mater. 29(41), 1605242 (2017). https://doi.org/10. 1002/adma.201605242

45. Y. Liu, J. Sun, Z. Yang, D. Yang, X. Ren, H. Xu, Z. Yang, S.F. Liu, 20-mm-large single-crystalline formamidinium-perovskite wafer for mass production of integrated photodetectors. Adv. Opt. Mater. 4(11), 1829-1837 (2016). https://doi.org/10.1002/adom. 201600327

46. M.I. Saidaminov, M. Haque, M. Savoie, A.L. Abdelhady, N. Cho et al., Perovskite photodetectors operating in both narrowband and broadband regimes. Adv. Mater. 28(37), 8144-8149 (2016). https://doi.org/10.1002/adma.201601235

47. V. Liberman, M. Rothschild, O. Bakr, F. Stellacci, Optical limiting with complex plasmonic nanoparticles. J. Opt. 12(6), 065001 (2010). https://doi.org/10.1088/2040-8978/12/6/065001

48. E. Chong, T. Watson, F. Festy, Autocorrelation measurement of femtosecond laser pulses based on two-photon absorption in gap photodiode. Appl. Phys. Lett. 105(6), 062111 (2014). https://doi. org/10.1063/1.4893423

49. W.R. Zipfel, R.M. Williams, Nonlinear magic: multiphoton microscopy in the biosciences. Nat. Biotechnol. 21(11), 1369-1377 (2003). https://doi.org/10.1038/nbt899

50. W. Haske, V.W. Chen, J.M. Hales, W. Dong, S. Barlow, S.R. Marder, J.W. Perry, $65 \mathrm{~nm}$ feature sizes using visible wavelength 3-D multiphoton lithography. Opt. Express 15(6), 3426-3436 (2007). https://doi.org/10.1364/OE.15.003426

51. G. Walters, B.R. Sutherland, S. Hoogland, D. Shi, R. Comin, D.P. Sellan, O.M. Bakr, E.H. Sargent, Two-photon absorption in organometallic bromide perovskites. ACS Nano 9(9), 9340-9346 (2015). https://doi.org/10.1021/acsnano.5b03308

52. Q. Lin, A. Armin, P.L. Burn, P. Meredith, Near infrared photodetectors based on sub-gap absorption in organohalide perovskite single crystals. Laser Photonics Rev. 10(6), 1047-1053 (2016). https://doi.org/10.1002/lpor.201600215

53. B. Yang, X. Mao, S. Yang, Y. Li, Y. Wang, M. Wang, W. Deng, K. Han, Low threshold two-photon-pumped amplified spontaneous emission in $\mathrm{CH}_{3} \mathrm{NH}_{3} \mathrm{PbBr}_{3}$ microdisks. ACS Appl. Mater. Interfaces 8(30), 19587-19592 (2016). https://doi.org/10.1021/ acsami.6b04246 